\title{
SOBRE A \\ INCOATIVIDADE \\ DOS VERBOS \\ TERMINADOS \\ EM -ECER EM \\ PORTUGUÊS ${ }^{1}$
}

\section{SOBRE LA INCOATIVIDAD DE LOS VERBOS TERMINADOS EN -ECER EN PORTUGUÉS}

\author{
ON THE INCHOATIVITY OF THE PORTUGUESE VERBS ENDING IN -ECER
}

Rui Pereira*

Universidade de Coimbra

RESUMO: A tradição gramatical portuguesa assume geralmente que -ecer é um constituinte sufixal característico de verbos incoativos, ou seja, verbos que exprimem o início de um estado ou processo. Neste artigo, procuraremos averiguar em que medida este proclamado valor aspetual dos verbos terminados em -ecer se encontra atestado no português contemporâneo ou em alguma(s) das fases pretéritas da nossa língua. Para esse efeito, analisa-se o significado de cinco verbos terminados em -ecer (adormecer, amanhecer, amarelecer, apodrecer, endurecer) ao longo do seu percurso diacrónico, com base nas atestações encontradas no CIPM Corpus Informatizado do Português Medieval e em obras lexicográficas editadas a partir do século XVI. Os dados permitem concluir que, desde o português antigo, os verbos em -ecer, mais do que expressar um evento no seu início, denotam eventos que focalizam o estado final da mudança sofrida por uma entidade.

PALAVRAS-CHAVE: Morfologia. Derivação. Sufixo. Aspeto. Incoativo.

RESUMEN: La tradición gramatical portuguesa generalmente asume que -ecer es un constituyente sufijal característico de los verbos incoativos, es decir, verbos que expresan el comienzo de un estado o proceso. En este ensayo trataremos de averiguar hasta qué punto este valor aspectual proclamado de los verbos terminados en -ecer se puede comprobar en el portugués contemporáneo o en alguna/s de las etapas pasadas de nuestra lengua. Para ello, se analiza el significado de cinco verbos terminados en -ecer (adormecer 'dejarse dormir, dormir a alguien', amanhecer 'amanecer', amarelecer 'amarillear', apodrecer 'pudrir', endurecer 'endurecer') a lo largo de su trayectoria diacrónica, partiendo de los ejemplos recogidos en el CIPM - Corpus Informatizado do

\footnotetext{
${ }^{1}$ Nota do Editor: mantivemos o texto em PE.

*Professor auxiliar da Faculdade de Letras da Universidade de Coimbra e membro integrado do CELGA-ILTEC, unidade de I\&D, fazendo parte da equipa de investigação que se debruça sobre morfologia e semântica da formação de palavras do português. E-mail: rui.pereira@uc.pt.
} 
Português Medieval, y en obras lexicográficas editadas desde el siglo XVI. Los datos permiten concluir que, desde el portugués antiguo, los verbos en -ecer, más que expresar un evento en su inicio, manifiestan eventos que se enfocan en el estado final del cambio sufrido por un ente.

PALABRAS CLAVE: Morfología. Derivación. Sufijo. Aspecto. Incoativo.

ABSTRACT: The Portuguese grammatical tradition generally assumes that -ecer is a suffix component characteristic of inchoative verbs, in other words, verbs that express the beginning of a state or process. In this article, we will seek to determine the extent to which this aspectual value of the verbs ending in -ecer is attested in both contemporary Portuguese and earlier stages of the language. For that purpose, we will analyse the meaning of five verbs ending in -ecer (adormecer 'to fall asleep', amanhecer 'to dawn', amarelecer 'to yellow', apodrecer 'to rot', endurecer 'to harden') along their diachronic path based on instances found in the CIPM - Corpus Informatizado do Português Medieval and lexicographic corpora published from the 16th century onwards. The available data allow us to conclude that as early as Ancient Portuguese, verbs ending in -ecer denote events that focus on the final stage of the change suffered by an entity, rather than expressing an event in its beginning.

KEYWORDS: Morphology. Derivation. Suffix. Aspect. Inchoative.

\section{ENQUADRAMENTO TEÓRICO E OBJETIVOS}

A tradição gramatical e lexicográfica têm salientado o valor 'incoativo' dos verbos que integram o constituinte sufixal -ecer ${ }^{2}$, designando com esse termo o significado aspetual de "acção incipiente" (PIEL, 1976, p. xxvi), "[...] começo de um estado ou processo [...]" (CÂMARA JR., 1979, p. 227; CUNHA; CINTRA, 1994, p. 102), ou "[...] início de ação ou passagem para um novo estado ou qualidade [...]" (BECHARA, 1999, p. 364) Neste sentido, 'incoativo' opõe-se a 'permansivo' e 'conclusivo', que designam, respetivamente, os valores aspetuais de desenvolvimento e fim de um evento (CUNHA; CINTRA, 1994, p. 380-381).

Todavia, nos estudos de semântica e de sintaxe que marcaram o final do século XX e o início deste século, o termo é usado num outro sentido. Na descrição das estruturas léxico-conceptuais dos verbos, nomeadamente dos verbos denominais e deadjetivais, $\mathrm{O}$ termo incoativo é utilizado por oposição a causativo (ver, entre outros, HASPELMATH, 1993; LABELLE, 1992; LEVIN; RAPPAPORT HOVAV, 1994, 1996, 1998; LIEBER, 1997, 2004; PIÑON, 2001; RAPPAPORT; LEVIN; LAUGHREN, 1988; RAPPAPORT HOVAV; LEVIN, 1998). Nestas abordagens, assume-se que verbos como amolecer, entristecer, esclarecer ou escurecer denotam eventos complexos compostos por dois subeventos: um evento AGIR que funciona como causa de um evento INCOATIVO, que designa a mudança de estado sofrida por uma entidade. Por exemplo, Levin e Rappaport Hovav (1998, p. 251) decompõem o significado do verbo causativo de mudança de estado to dry ('secar') como (1); nesta representação, $x$ e $y$ são variáveis que representam os argumentos do verbo, sendo $d r y$ ('seco') uma constante que representa o estado associado ao verbo to $d r y$.

$$
d r y:[[\mathrm{x} \text { ACT }] \text { CAUSE [y BECOME DRY]] }
$$

Na mesma linha, em Pereira (2007, p. 21) representa-se a estrutura léxico-conceptual (ELC) e a estrutura argumental (EArg) do verbo endurecer, presente numa frase como O Governo endureceu as medidas de combate à covid-19, do seguinte modo:

$$
\text { endurecer: } \mathrm{V}
$$

ELC: [[ $x$ AGIR $]$ CAUSAR [ $y$ IR PARA DURO $]]$

EArg: $\underline{x}, y$

Ao nível semântico, o verbo endurecer expressa um evento no qual o argumento $x$ produz ou causa uma mudança de estado - de um estado não especificado para [+ duro] - no argumento $y$. Ao nível argumental, especifica-se que as variáveis $\underline{x}$ e $y$ correspondem,

\footnotetext{
${ }^{2}$ Por questões de simplicidade de descrição, usaremos a configuração de infinitivo (-ecer) para nos referirmos ao elemento sufixal em análise, embora se reconheça que esta terminação compreende três constituintes morfológicos distintos: -ec sufixo derivacional + e vogal Temática $+\mathrm{r}$ Sufixo de Infinitivo.
} 
respetivamente, aos argumentos externo (O Governo) e interno (as medidas de combate à covid-19) do verbo derivado. Ao invés, a constante DURO não tem projeção argumental uma vez que é incorporada no radical do verbo derivado.

Noutros enunciados, porém, o verbo endurecer é usado em construções correlatas não causativas, designadas incoativas, como se atesta em (3b). Este fenómeno é conhecido como "alternância causativa” (cf. ALEXIADOU, 2015; BORER, 1991; FONSECA, 19981999; RAPPAPORT HOVAV; LEVIN, 2012; SCHÄFER, 2009).

a. O Governo endureceu as medidas de combate à covid-19. (construção causativa)

b. As medidas de restrição endureceram.(construção incoativa)

A diferença entre causativo e incoativo ${ }^{3}$ expressa-se (i) pela diferença no número de argumentos participantes, relacionada com a expressão ou omissão do argumento externo que designa a entidade causadora, e (ii) a distinta disposição sintática do argumento interno, uma vez que a expressão linguística que designa a entidade afetada ocorre como objeto direto na estrutura transitiva causativa (cf. 3a), mas figura como sujeito nas estruturas intransitivas incoativas (cf. 3b). Na representação lexical do verbo endurecer (cf. 2), a opcionalidade da expressão da entidade causadora é representada através dos parênteses e do negrito na ELC e pelo sublinhado do argumento externo $\underline{x}$ na EArg.

Neste artigo, iremos analisar o significado dos verbos em -ecer ao longo da história do português. Pretende-se, em particular, averiguar em que medida se pode afirmar (ou não) que a incoatividade é uma propriedade específica dos verbos em -ecer. A questão que pretendemos ver respondida é a seguinte: os verbos em -ecer possuem ou possuíram em algum estádio da língua portuguesa um valor aspetual 'incoativo', exprimindo eventos na sua fase inicial. Para dar resposta a esta questão, na secção 1, iremos analisar a expressão da incoatividade em latim, observando a evolução do significado dos verbos em -escere naquela língua; de seguida, analisase o modo como o português dá (ou não) continuidade ao sistema latino, avaliando o valor semântico-aspetual dos verbos em -ecer ao longo do seu percurso diacrónico.

\section{VERBOS LATINOS TERMINADOS EM -ESCERE}

Os verbos terminados em -ecer aparecem frequentemente, seja em gramáticas seja em dicionários do português, associados à noção de 'incoatividade', assumindo-se que se trata de um esquema construcional importado da língua latina (cf. 1 e 2).

“-ecer [Do lat. ...escere.] suf. Suf. verb., de origem latina, característico dos verbos incoativos, ou seja, que exprimem o início de um estado e, por vezes, o seu desenvolvimento: alvorecer, embranquecer, escurecer." (FIGUEIREDO, 1996, p. 904).

“-ecer term. de v. latinos em -escere (ver -ESCER); a sua fecundidade como incoativo cedo se manifestou em port. nos v. da 2. ${ }^{\text {a }}$ conj., fecundidade que perdurou na língua por largo lapso de tempo, originando grande número de tais v. com radicais vulg. e vern. [...].” (HOUAISS; VILLAR; FRANCO, 2003, p. 1420).

Embora existam em latim muitos verbos terminados em -escere que expressam eventos incoativos, não é uniforme o valor semântico dos verbos com esta terminação naquela língua, nem é essa a função original do afixo -sc-. Em estádios antigos do latim, do grego e de outras línguas indo-europeias, servia o constituinte afixal -sc- (ou -sk-) para formar o tema do presente. Por exemplo, em latim, a forma de perfeito de crescere é crevi e a de inveterasco é inveteravi, tornando-se evidente que -sc- ocorre no presente, mas não no perfeito (ALLEN, 1995, p. 3; ILIESCU, 1990, p. 161).

\footnotetext{
${ }^{3}$ Alguns autores preferem as designações decausativo ou anticausativo (cf. ALEXIADOU, 2010, 2015; FONSECA, 1998-1999; HÄRTL, 2003; KOONTZGARBODEN, 2009; LEVIN; RAPPAPORT HOVAV, 1998; PIÑON, 2001; RAPPAPORT HOVAV; LEVIN, 2012; RAPPAPORT HOVAV, 2020).
} 
Do contexto flexional, o sufixo transita para o contexto derivacional, passando a construir verbos com significado incoativo ${ }^{4}$ a partir de verbos deadjetivais da segunda conjugação. Consequentemente, o latim passa a exibir séries derivacionais do seguinte tipo: um adjetivo (senex 'velho'), um verbo estativo da segunda conjugação (senere 'ser velho') e um verbo incoativo (senescere 'ficar velho/começar a ser velho'). Dado que o sufixo latino - sc- tomou uma função gramatical diferente do seu papel inicial, pode-se dizer que sofreu um processo de regramaticalização, definida por Greenberg (1991, p. 301) como uma "reinterpretation in a new function", resultante da extensão a novos ambientes semânticos. Posteriormente, o sufixo espalha-se a verbos que indicam estádios/fases da vida dos seres humanos (iuvenis > iuvenescere), plantas (flos > florescere), doenças (tabes $>$ tabescere) e perceções sensoriais ou intelectuais (calere > calescere; scire > sciscere) (ALLEN, 1995, p. 3).

No latim clássico, alguns verbos incoativos tornam-se transitivo-causativos (BLAYLOCK, 1975, p. 437; ZAMBONI, 1982-83, p. 92). Por exemplo, o Oxford Latin Dictionary (GLARE, 1983) apresenta como verbos transitivos expallescere 'tornar pálido’ e horrescere 'causar medo'. Segundo Zamboni (1982-83, p. 92), este desenvolvimento semântico terá sido motivado pelo facto de a classe de verbos em - $i$ - (4. ${ }^{a}$ conjugação) conter um grande número de verbos deadjetivais com função causativa como mollire, lenire, donde a extensão deste traço às formas incoativas, que se tornaram assim causativas.

Iliescu (1990) constata que o valor causativo do sufixo -sc- resulta de um processo de neutralização que começa a verificar-se no século I a.C. Segundo esta autora, no latim clássico, os verbos incoativos ("deventivos" na sua terminologia) com o sufixo -sc- têm como correspondente um verbo causativo, que pertence na maioria dos casos à 1. a conjugação.

\begin{tabular}{c|c|c} 
& Verbos causativos & Verbos incoativos \\
\hline dis 'rico' & dito 'tornar rico' & ditesco 'ficar rico' \\
\hline lassus 'cansado' & lasso 'cansar' & mitesco 'ficar doce' \\
\hline mitis 'doce' & mitio 'tornar doce' cansado' & spissesco 'ficar denso' \\
\hline spissus 'denso' & spisso 'tornar denso' & crassesco 'ficar grosso'
\end{tabular}

Quadro 1: Verbos causativos e incoativos derivados em latim

Fonte: Iliescu (1990, p. 164)

No entanto, muitos destes verbos causativos expressavam também um sentido incoativo quando o verbo era usado intransitivamente, contribuindo assim para a perda gradual da oposição entre causativo e incoativo (duro: 'tornar duro', 'ficar duro'). Se a esta situação acrescentarmos a tendência geral do latim tardio de substituir as formas mais curtas pelas mais longas, compreende-se por que motivo os verbos terminados em -escere passaram a acumular os dois valores semânticos.

A substituição das formas simples pelas formas com sufixo (acompanhado ou não de um prefixo) teve como consequência que um só verbo podia exprimir o que se exprimia em latim clássico por um par, seja estativo vs. incoativo, seja causativo vs. incoativo. $\mathrm{O}$ resultado foi a sinonímia entre verbos com e sem afixo(s), fenómeno que não estava apenas limitado aos verbos em -escere, e a neutralização e simplificação do sistema derivacional. Iliescu (1990, p. 165) representa esquematicamente a evolução dos sentidos dos verbos com o sufixo -sc- da seguinte forma:

\footnotetext{
${ }^{4}$ Segundo Allen (1995, p. 2), -sk- desenvolveu noutras línguas indo-europeias significados diferentes do sentido incoativo. O hitita, por exemplo, tem verbos com $s k$ - iterativos e no dialeto jónico do grego homérico encontram-se imperfeitos iterativos; nos poemas homéricos, estão atestados ainda aoristos iterativos em -sk-.
} 
1. 'tornar duro'

2. 'ficar duro'

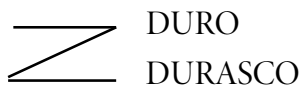

DURASCO
DURO

DURASCO
1. 'tornar duro'

2. 'ficar duro'

1. 'tornar duro'

2. 'ficar duro'

Quadro 2: Neutralização da oposição causativo/incoativo em latim

Fonte: Iliescu (1990, p. 165)

Uma explicação semelhante é fornecida por Pena (1993). Segundo este autor, em latim, a partir de verbos de tema em -ē- (simples ou derivados), que denotavam um estado ou situação, formaram-se com grande regularidade verbos em -escere de aspeto incoativo, i.e., verbos que expressam a entrada nesse estado ou situação. Paralelamente, também com bastante regularidade, sobre o adjetivo em -id- e o substantivo em -or correspondentes ao verbo de tema em -ē-, formavam-se verbos de tema em - $\bar{a}$ - para indicar a causalidade de tal estado ou situação (cf. Quadro 3).

\begin{tabular}{|c|c|c|}
\hline Verbos estativos & Verbos incoativos & Verbos causativos \\
\hline carēre & carēscere & \\
\hline dolēre & dolēscere & \\
\hline timēre & timēscere & \\
\hline calēre & calēscere & calidāre \\
\hline frīgēre & frīgēscere & frīgorāre, frīgidāre \\
\hline dulcēre & dulcēscere & dulcāre, dulcificāre, (e)dulcorāre \\
\hline dūrēre & dūrēscere & dūrāre \\
\hline \multirow[t]{3}{*}{ nigrēre } & nigrēscere & nigrāre, nigrificāre \\
\hline & amārēscere & amārāre, amāricāre, amārificāre \\
\hline & sānēscere & sānāre \\
\hline
\end{tabular}

Quadro 3: Verbos estativos, incoativos e causativos derivados em latim

Fonte: Pena (1993, p. 264)

Em latim, existiam, portanto, séries ternárias de verbos aspetualmente diferenciados: estativos (calère 'estar quente'), incoativos (calēscere 'entrar no estado de quente') e causativos (calidāre 'fazer com que fique quente'). Todavia, com o passar do tempo, esta situação deixa de se manter com a regularidade anterior: não só -sc- se expande para fora do âmbito dos verbos de tema em - $\bar{e}-$, passando a acoplar-se também a bases nominais e adjetivais, como passa a expressar as noções contíguas, especialmente a causatividade.

\section{SIGNIFICADO DOS VERBOS EM -ECER EM FASES PRETÉRITAS DO PORTUGUÊS}

Como vimos, não é uniforme o significado dos verbos latinos terminados em -escere que transitam para as línguas romance, tendo o português incorporado verbos que evidenciam diferentes estádios evolutivos deste sufixo. No DVPM (Dicionário de Verbos do 
Português Medieval) estão registrados cerca de 66 verbos terminados em -ecer, a que acrescem 3 verbos em -scer (crescer, nascer, reenascer), mas o número será menor se agruparmos os casos de variação formal (e.g. acaecer/aquecer, amanhecer/hamanhecer). Em termos morfológicos, podemos encontrar (i) verbos não analisáveis em português (e.g. crescer, parecer, aborrecer), (ii) verbos deverbais (e.g. acrecer, adormecer, desaparecer, desconhecer, desobedecer, desperecer, reenascer), e (iii) verbos denominais e deadjetivais (e.g. alvorecer, blandecer, amarelecer, avilecer, emvelhecer, endurecer, esclarecer). Existem ainda vários casos em que a forma circunfixada coexiste com a forma sem constituinte prefixal (e.g. aluzecer/luzecer, amadurecer/madurecer, amanhecer/manhecer, apodrecer/ podrecer).

Tendo em vista a análise do valor semântico dos verbos em -ecer, levamos a cabo um estudo que pretendia responder às seguintes questões: o que caracteriza este tipo de verbos em português do ponto de vista semântico? As propriedades semânticas destes verbos variam ao longo da diacronia do português? Para realizar esta análise, selecionamos um conjunto de 5 verbos (adormecer, amanhecer, amarelecer, apodrecer, endurecer), que cobrem várias estruturas morfolexicais: verbos sufixados e circunfixados; verbos deverbais, denominais e deadjetivais. A nossa análise incidiu sobre as descrições que destes verbos são feitas em obras lexicográficas de diversas épocas. Uma vez que o primeiro dicionário referente ao português data do século XVI, para a descrição dos verbos no português antigo, recorremos ao CIPM - Corpus Informatizado do Português Medieval.

Apresentam-se, de seguida, os dados apurados relativamente ao(s) significado(s) dos verbos em -ecer selecionados em diferentes estádios da língua portuguesa.

\subsection{CORPUS INFORMATIZADO DO PORTUGUÊS MEDIEVAL (CIPM)}

\section{ADORMECER}

A maioria das ocorrências deste verbo deverbal encontradas no CIPM é marcada pela ideia de incoatividade, expressando o significado de 'começar a dormir'. Vejamos alguns exemplos:

$$
\text { “[... mandei-lhi fazer / mui boa cama, e adormeceu” (Cantiga de Escárnio e Maldizer de Fernão Garcia Esgaravunha). }
$$

"pôs cabo de si e adormeceu" (Cantiga de Escárnio e Maldizer de João Garcia de Guilhade).

do Conde D. Pedro de Meneses)

É especialmente elucidativa a distinção que é estabelecida em (13) entre adormecer, o verbo incoativo, e dormir, o verbo que lhe serve de base. Como o exemplo (13) evidencia, ao evento designado por adormecer sucede naturalmente o processo dormir.

"[...] e conte plando todo aquelle dia / e noite em aquellas cousas, que auia visto adormeçeo, e dormio em pax."

(Crónica D. João I) 
O sentido causativo é conseguido, nesta época, através do recurso ao sufixo - entar ${ }^{5}$ ou então, de forma sintática, pelo uso do verbo auxiliar fazer (itálico nosso).

"E canta muy doceme te, e $\sim$ tal guisa que co a dulçura do seu cantar faze $\sim$ adormecer os mareantes. [...] faze $\sim$-nos periguar e no mar depois que som adorme tados. E pore Vlixes de Troya [...] fez muy bem tapar as orelhas a todos os seus mareantes por no $\sim$ ouuire os cantos dellas, por tal que no adormecessem ne $\sim$ periguassem enno mar [...]" (Orto do Esposo)

\section{AMANHECER}

O verbo amanhecer é usado com o sentido de processo que culmina num estado, 'ser manhã'.

"[...] e corre o campo nelle a hu a parte e a outra atee que amanhece, por que tudo ysto faz ante manhaa." (Crónica dos Reis de Bisnaga)

(16) "- Sen(h)or, chegou ally o allmocade , \& pareçe-me que diz q(ue) lhe he neçessario de vos fallar llogo amte que amanheça." (Crónica do Conde D. Pedro de Meneses)

"E dize alguu s que qual quer que ãte que hamanheça / diz a myssa, peca mortalmente" (Sacramental)

Na expressão deste sentido, o verbo amanhecer é, por vezes, substituído pelos verbos denominais aluzecer (cf. 18) e alvorecer (cf. 19).

$$
\text { "[...] e andarom assi ataa que aluzeceu." (Demanda do Santo Graal) }
$$

"[...] e na alva da manhãa tamto que alvoreçeo, os Gallegos estavom ja todos prestes [...]” (Crónica de D. João I)

Quando se pretende focalizar o ponto inicial do processo, recorre-se ao verbo auxiliar aspetual começar (de). "[...] e suas ge tes forom logo jumtas com eu, e armados todos e prestes, começando ja damanhecer." (Crónica de D. João I)

$$
\begin{aligned}
& \text { "[...] e quamdo sse levantarom e começou de amanheeçer [...]" (Crónica de D. João I) } \\
& \text { "[...] desque paresçe alguma cousa de luz e / começa amanhecer [...]” (Sacramental) }
\end{aligned}
$$

\section{AMARELECER}

Na única atestação encontrada no CIPM, o verbo deadjetival amarelecer ('ficar amarelo', 'passar a ser amarelo') é precedido do verbo auxiliar aspetual começar de, focalizando-se assim o ponto inicial do processo de mudança de estado designado pelo verbo amarelecer. e braadar altas uozes, pidindo espaço." (Orto do Esposo).

\footnotetext{
${ }^{5}$ Sobre o valor semântico dos verbos terminados em -entar e a sua relação com os verbos em -ecer, veja-se Pereira (2020).
} 


\section{APODRECER}

Na maioria dos casos, o verbo apodrecer ocorre em estruturas inacusativas, designando um processo de transformação natural ou internamente causado que culmina na obtenção do estado 'podre'.

(24) "Conta hu u $\sim$ sabedor, que ha nome Plinio, que ha hu a aruore en Terra de Jndia, que nu ca apodrece a madeyra della ne a pode queymar o fogo." (Orto do Esposo)

"E a sua augua he muy conffortativa e esta sempre na humydade natural e as arvores aadur apodrece hy e as hervas nu ca se secam tanto que falleça pasto." (Crónica Geral de Espanha)

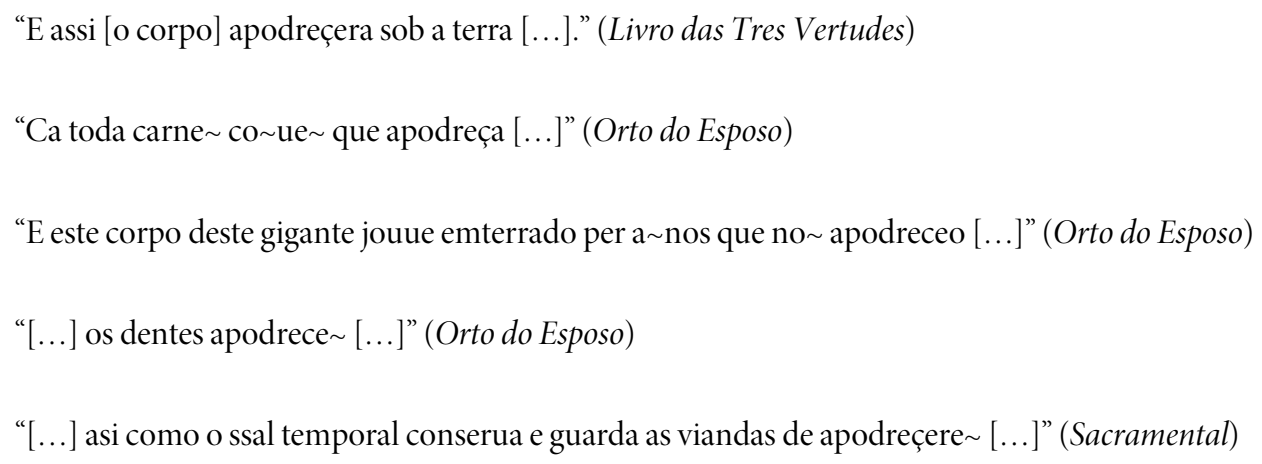

No entanto, o verbo apodrecer também é usado com valor causativo. No Sacramental, incunábulo de finais do século XV, há uma ocorrência de apodrecer numa estrutura transitiva (cf. 32), com o objeto afetado ("os outros" [dentes]) a ocupar a posição de complemento direto.

"[...] assy como faz o que tem huu dente apodreçido que ha door que o tira por que nom apodreça os outros e sse tira a door." (Sacramental)

No mesmo documento, existe ainda uma ocorrência em que o verbo apodrecer é seguido do clítico sse e onde a causa do processo de transformação surge como um modificador preposicional ("en pecados”).

"[...] asy este sal que he spiritual guarda a alma de apodreçersse en pecados e lhe da sabedoria por que sse guarde de pecar." (Sacramental).

\section{ENDURECER}

O verbo endurecer designa um processo que culmina na obtenção do estado 'duro'. Em resultado do processo designado por este verbo, algo ou alguém fica "emduriçido" ou "e dureçida" (Sacramental, 1488).

Este verbo está atestado quer em construções incoativas, designando uma mudança de estado sofrida por uma entidade (aumento do seu grau de dureza), quer em construções causativas. No uso incoativo, comporta-se como um verbo inacusativo, podendo ser acompanhado do clítico sse. 
No uso causativo, é o verbo de uma estrutura transitiva (cf. 35), cujo argumento externo expressa a causa ("o ssol") e o argumento interno, o objeto afetado ("o llodo").

$$
\text { “De^s i, o ssoll faz derreter os enguent(os) aroma 'tic(os) e seca e endurece o llodo." (Castelo Perigoso) }
$$

Refira-se ainda que, nesta fase da língua portuguesa, a par do verbo endurecer, existe o verbo endurentar, formado sobre a mesma base adjetival (duro).

$$
\text { "Ca as rriquezas som estercos emgrosados e e } \text { durentados [...]" (Orto do Esposo) }
$$

Em resumo, no português antigo, os verbos em -ecer expressam valores semânticos diversos. O verbo adormecer, verbo deverbal construído a partir de dormir, foca a fase inicial de um processo ('começar a dormir'), podendo por isso ser classificado como um verbo incoativo, no sentido aspetual ('incetivo') que é atribuído a este termo. Os restantes verbos, denominais (amanhecer) ou deadjetivais (amarelecer, apodrecer, endurecer), designam processos que culminam na obtenção de um estado. Ao contrário de amanhecer, para o qual apenas está atestado o uso incoativo, os verbos deadjetivais podem ocorrer em construções causativas ou incoativas, no sentido semântico-argumental deste termo. Na expressão do aspeto 'incetivo', estes verbos são precedidos pelo verbo auxiliar começar (de).

\subsection{DICIONÁRIO DE JERÓNIMO CARDOSO (SÉC. XVI)}

O dicionário de Jerónimo Cardoso (1562-1563) atesta uma situação semelhante à encontrada no português antigo. Este dicionário dá conta da possibilidade de os verbos em -ecer poderem expressar eventos causativos (adormecer a outrem, apodrecer a outrem, endurecer a outrem) a par de eventos incoativos (adormecerse, apodrecerse, endurecerse), isto é, eventos que designam uma mudança de estado não causada ou naturalmente causada. Excetuam-se amanhecer (apenas descrito como v.) e amarelecer, para o qual está referenciado apenas o uso incoativo (amarelecerse, amarelo fazerse). Com a exceção de amanhecer, quase todos os verbos admitem o uso do clítico se na expressão da incoatividade.

\section{3 “VOCABULARIO PORTUGUEZ E LATINO” DE BLUTEAU (SÉC. XVIII)}

A alternância causativo/incoativo está também documentada no Vocabulario Portuguez e Latino (1712-1728), de Raphael Bluteau, para os verbos adormecer, apodrecer e endurecer ${ }^{6}$, mantendo-se nestes verbos a associação do clítico se ao sentido incoativo dos verbos em causa.

$$
\text { "ADORMECER, ou adormecerse. Começar a dormir./ Adormecer a outrem." }
$$

“APODRECER. Alterar pouco a pouco, corromper, dissolver o mixto, segregando as partes / APODRECERSE.”

"ENDURECER alguma cousa, fazella dura. / ENDURECERSE. Fazerse duro."

O verbo amarelecer deixa de ter entrada nesta base de dados lexical, sendo substituído na expressão de «Fazerse amarello» pelo verbo amarellejar.

\footnotetext{
${ }^{6}$ Esta dupla possibilidade de atualização no discurso é comum a muitos outros verbos deadjetivais referenciados neste dicionário: "ESCURECER. Suspender a acçaõ da luz; escurecer-se"; "ENRIQUECER. Fazer rico; Dar riquezas; Fazerse rico"; "EMPOBRECER. Ficar pobre; Empobrecer a outrem"; "EMMAGRECER. Fazer a alguém magro; Fazerse magro"
} 
O verbo amanhecer apenas está atestado com valor não causativo (“Alvorar a menhãa”). Bluteau apresenta, no entanto, a possibilidade de o verbo ter usos pessoais: "Amanhecer, tanbem se diz de huma pessoa, que faz alguma cousa muito pella menhãa. Amanheci hoje na feira."

O aspeto incetivo ('início de ação') apenas é referido explicitamente em relação ao verbo deverbal adormecer. Nos outros casos, principalmente nos verbos deadjetivais, começa a ser anotado o aspeto durativo e gradual da mudança de estado designada pelos verbos (e.g. "APODRECER. Alterar pouco a pouco [...]"). ${ }^{7}$

\subsection{DICIONÁRIO DE MORAES SILVA (SÉC. XVIII)}

Elaborado em 1789 a partir do Vocabulario Portuguez e Latino de Bluteau, este dicionário não apresenta em relação aos verbos sob escopo grandes alterações. Excetua-se a inclusão novamente do verbo amarellecer.

Para os verbos adormecer, amarellecer e apodrecer apresentam-se dois usos, como verbos ativos ( $v$. at.) e verbos neutros ( $v$. n.), que correspondem aos usos causativo e incoativo, respetivamente. “ADORMECER, v. at. Causar sono, fazer dormir. Neutro. Ficar preso no sono.”

“AMARELLECER, v. at. Fazer amarello. v. $n$. fazer-se amarello." corromper-se, passar á fermentação podre."

\subsection{DICIONÁRIO DE DOMINGOS VIEIRA (SÉC. XIX)}

Este dicionário, publicado entre 1871 e 1874, fornece muito mais informação que os anteriores, quer em termos de etimologia, quer em termos semânticos, com descrições mais detalhadas, acompanhadas de atestações para os diferentes sentidos e usos.

Domingos Vieira refere-se explicitamente ao valor aspetual incoativo (ou incetivo) da terminação -ecer na entrada do verbo adormecer. $^{8}$

“ADORMECER, v. a. (Do latim dormire, com a fórma inchoativa ou inceptiva escere, que denota acção no seu principio.) Cair pouco a pouco em somno; toscanejar; causar somno, adormentar, narcotisar os sentidos [...].

Adormecer, v. n. Começar a dormir, cair com somno, cabecear, dormitar, perder o movimento, cair em lethargia; figuradamente, descuidar-se."

Embora se refira que a terminação latina -escere, que está na origem deste verbo, transmite um valor incoativo, começa por classificar este verbo como um verbo ativo ( $v$. a.); aliás, a causatividade é expressa claramente no sentido "causar somno". O caráter incetivo do sufixo, de "acção no seu principio", aparece referido claramente a propósito do uso de adormecer como verbo neutro (cf. “Adormecer, v. n. Começar a dormir"), mas não nos outros verbos em análise.

\footnotetext{
${ }^{7}$ Este valor semântico-aspetual está também patente, por exemplo, na entrada do verbo enfraquecer, especialmente nas atestações que são apresentadas. Porque designa uma mudança de estado gradual, é possível focalizar o processo de enfraquecer no seu início (“Já começo a enfraquecer.") ou no seu progresso (“Todos os dias vay enfrequecendo.").

${ }^{8}$ Uma referência semelhante é feita a propósito do verbo anoitecer: "ANOITECER, v. n. (De noite, com o prefixo da índole da língua, e a terminação verbal inchoativa.)"(VIEIRA, 1871, p. 436).
} 
Em termos semântico-argumentais, apenas amanhecer tem um uso exclusivamente incoativo. Os restantes verbos sob escopo aliam o uso incoativo de "verbo neutro" a usos causativos de "verbo activo" (cf. adormecer, amarellecer, apodrecer, endurecer) e a usos de "verbo reflexo" (cf. amanhecer-se, apodrecer-se, endurecer-se).

\section{SEMANTISMO DOS VERBOS EM -ECER NO PORTUGUÊS ATUAL}

O constituinte sufixal -ecer está presente no português contemporâneo em mais de duas centenas de verbos, umas vezes atuando como único operador afixal (e.g. escurecer, humedecer, robustecer), outras vezes (a maioria) acompanhado de um constituinte prefixal, geralmente $a$-, en- ou es- (e.g. adormecer, endurecer, esclarecer), apresentando-se, em alguns casos, sob a forma -escer, mais próxima da matriz latina (e.g. florescer, enrubescer). Este sufixo tem a particularidade de ser o único que é usado atualmente na construção de verbos da $2 .{ }^{a}$ conjugação, selecionando a VT -e- .

$\mathrm{O}(\mathrm{s})$ significado(s) dos verbos derivados com -ecer são descritos nos dicionários através de paráfrases muito diversas, como 'tornar / ficar Xb' (escurecer, endoidecer), 'começar a ser Xb' (amanhecer, anoitecer), 'criar/ganhar Xb' (ervecer, florescer), causar/sentir Xb' (enraivecer, enfurecer), designando Xb a base lexical. Em Pereira (2007, 2016), estes verbos são repartidos por duas classes semânticas: (i) a maioria faz parte da classe de "verbos resultativos", entendidos como verbos que denotam uma mudança ou alteração nas propriedades de uma entidade (e.g. escurecer, fortalecer, robustecer, amadurecer, amolecer, emagrecer, enraivecer, esclarecer); (ii) atestam-se ainda alguns "verbos performativos", que denotam um evento no qual o sujeito faz ou cria um objeto (objeto efetuado) designado pela base derivacional (e.g. ervecer, embolorecer, emplumescer, encanecer, favorecer).

Estes verbos são geralmente interpretáveis como transições ${ }^{9}$ (simples ou graduais), ou seja, eventos que denotam a mudança que sofre uma entidade desde a não posse à posse de uma determinada propriedade ou estado (PUSTEJOVSKY, 1991). Assim, por exemplo, o verbo emudecer requer um participante que passe de um estado ('não estar mudo') para outro diferente ('estar mudo'), especificado pela base lexical mudo.

A designação transição aplica-se quer às mudanças de estado-de-coisas com uma estrutura temporal simples, i.e., que ocorrem num determinado ponto temporal, quer às mudanças graduais que culminam na obtenção de um determinado estado ${ }^{10}$. Por exemplo, emagrecer é um evento de mudança de estado que demora logicamente algum tempo a ocorrer; em contraste, emudecer é um evento pontual ou escassamente durativo. Em (44) e (45), representa-se esquematicamente a estrutura temporo-aspetual destes dois tipos de eventos.

$$
\begin{array}{ccc}
\multicolumn{2}{c}{\text { Transições simples }} \\
\mathrm{t}_{\mathrm{i}} & \mathrm{t}_{\mathrm{f}} & \text { 'linha temporal' } \\
\bullet & \bullet & \\
\mathrm{E}_{\mathrm{i}} & \mathrm{E}_{\mathrm{f}} & \text { 'trajeto da propriedade duma entidade' }
\end{array}
$$

$$
\begin{array}{cccccc}
\multicolumn{7}{c}{\text { Transições graduais }} \\
\mathrm{t}_{\mathrm{i}} & \mathrm{t}_{\mathrm{j}} & \mathrm{t}_{\mathrm{k}} & \ldots & \mathrm{t}_{\mathrm{f}} & \text { 'linha temporal' } \\
\bullet & \bullet & \bullet & \ldots & \bullet & \\
\mathrm{E}_{\mathrm{i}} & \mathrm{E}_{\mathrm{j}} & \mathrm{E}_{\mathrm{k}} & \ldots & \mathrm{E}_{\mathrm{f}} &
\end{array}
$$

Enquanto a linha temporal das transições simples é composta por apenas dois momentos conceptuais, o momento inicial $\left(\mathrm{t}_{\mathrm{i}}\right)$ e $\mathrm{o}$ momento final $\left(\mathrm{t}_{\mathrm{f}}\right)$, as transições graduais possuem uma estrutura temporal mais complexa, escalar, que integra, para além dos momentos inicial e final, $n$ pontos temporais intermédios $\left(t_{\mathrm{j}}, \mathrm{t}_{\mathrm{k}} \ldots\right)$.

\footnotetext{
${ }^{9}$ Sobre a estrutura eventiva destes verbos, vejam-se, entre outros, Pustejovsky (1991), Grimshaw (1990), Lieber (2004), Fernández Lagunilla e Miguel (1999) e Miguel e Fernández Lagunilla (2000).

${ }^{10}$ A estas duas classes de eventos télicos, Oliveira (2003, p. 134) dá o nome de culminações e de processos culminados, respetivamente.
} 
As transições simples são eventos pontuais delimitados que denotam uma mudança não gradual. Esta classe de predicados denota um evento que culmina num ponto e que implica uma fase posterior a esse ponto, um estado resultante, que é determinado pela base lexical. Uma prova de que este tipo de transições denota eventos que pressupõem duas fases reside no facto de admitirem ser modificados tanto por adverbiais pontuais (cf. 46a), como por adverbiais durativos (cf. 46b), dependendo da fase modificada em cada caso.
a. Ele emudeceu imediatamente.
b. Ele emudeceu durante dois minutos.

Em (46a), o modificador adverbial imediatamente revela a natureza pontual da estrutura temporal do evento denotado por emudecer. Já o modificador adverbial durativo presente em (46b) não especifica o intervalo de tempo que carateriza a realização do evento denotado pelo verbo emudecer, mas a duração do estado resultante desse evento. Não é o evento emudecer que dura dois minutos a acontecer, mas o correspondente estado resultante 'estar mudo'.

Comportam-se como transições simples os verbos construídos sobre adjetivos não graduáveis (emudecer) e os verbos denominais que significam 'causar N', em que a base nominal designa um 'sentimento' ou 'estado de espírito' (e.g. enfurecer, enraivecer, envaidecer, espavorecer). Estes verbos designam a transição de um estado de 'não ter/sentir N' para o estado de 'ter/sentir N', denotando eventos télicos pontuais ou de duração escassa.
a. Ele envaideceu-se naquele instante com as suas conquistas.
b. Aquela palavra enfureceu-o imediatamente.

As transições graduais, por sua vez, têm uma certa duração conceptual e alguma graduabilidade na sua interpretação (RAMCHAND, 1997; LIEBER, 2004). Distinguem-se das transições simples, entre outros aspetos, pelo seu comportamento em relação à perífrase de gerúndio (cf. 48) e ao operador aspetual ainda (cf. 49).

a. ${ }^{\star}$ Ele vai emudecendo lentamente.

b. A Maria vai emagrecendo lentamente.

a. ${ }^{*}$ Ele ainda está a emudecer.

b. A Maria ainda está a emagrecer.

Verbos como amadurecer, amolecer, emagrecer, endurecer, envelhecer, escurecer implicam uma mudança de estado paulatina, ao longo de uma escala de valores, e um limite final, comportando-se como eventos durativos delimitados. Por isso, admitem ser interpretados como 'progressivos' e como 'conclusivos' ou 'terminativos'. Por exemplo, os eventos desta classe podem ser contemplados no seu desenvolvimento intermédio, em progresso, daí a sua compatibilidade com construções progressivas.
a. A manteiga amoleceu pouco a pouco.
b. Esta blusa está a amarelecer cada vez mais.
c. O João está a envelhecer de dia para dia.

Estes verbos também admitem que se focalize a fase final do evento, em que a mudança ocorreu e o evento acabou.
a. A manteiga amoleceu completamente.
b. Esta blusa amareleceu por completo.
c. O João envelheceu.

Os verbos que denotam transições graduais são compatíveis quer com adverbiais pontuais, quer com adverbiais durativos. 

a. A Terra escureceu às dez horas/ durante dois minutos.
b. A Ana humedeceu o bolo às dez horas/ durante dois minutos.

O modificador adverbial às $x$ horas focaliza o momento em que o limite final da transição denotada pelos verbos escurecer e humedecer é atingido. Por sua vez, o adverbial temporal durante $x$ tempo permite focalizar a fase que antecede a culminação dos eventos, pondo em evidência que se trata de eventos durativos, em que a cada novo ponto temporal se pode dizer que 'está mais escuro/húmido do que estava antes'.

Existe um pequeno grupo de verbos denominais que apresenta um comportamento similar. Referimo-nos aos verbos amanhecer, entardecer e anoitecer.
a. Amanheceu às seis e anoitecerá às vinte horas.
b. Já amanheceu/anoiteceu.
c. Vai amanhecendo/anoitecendo pouco a pouco.
d. Entardecia.

Tal como os verbos anteriores, estes verbos denotam transições graduais, i.e., processos durativos que culminam num ponto em que se atinge um determinado estado. As frases (53c) e (53d) focalizam a mudança gradual, enquanto (53a) e (53b) focalizam o momento em que se dá a entrada num novo estado (às seis horas é manhã, às vinte horas é noite) ou em que a transição é dada como terminada (neste momento já é manhã/noite).

Quando denotam eventos durativos delimitados, os verbos em -ecer são compatíveis com as perífrases aspetuais começar a e deixar de, que focalizam, respetivamente, o início e a cessação do evento.
a. A Ana começou a/deixou de humedecer o bolo.
b. O trigo começou a lourecer/deixou de lourecer.
c. O dia começou a escurecer/deixou de escurecer.

A compatibilidade com verbos auxiliares de aspeto incetivo (começar a...) e cessativo (deixar de...) enfraquece a tese segundo a qual os verbos em -ecer designam o 'início de um estado ou processo' e daí a classificação de 'incoativo', no sentido em que este termo é tomado em várias gramáticas e dicionários.

Tratando-se de eventos que culminam num ponto, os verbos derivados com -ecer são verbos télicos, como se comprova pela compatibilidade com o adverbial de realização em x tempo.

$$
\begin{aligned}
& \text { a. Estas bananas apodrecem em dois dias. } \\
& \text { b. O tomate vai amadurecer em dois dias. }
\end{aligned}
$$

As transições graduais são, portanto, eventos com uma estrutura temporal complexa que culminam num ponto. Por esse motivo, admitem construções em que se focaliza ora o estado resultante, ora o processo que conduz à obtenção desse estado. A base lexical destes verbos derivados especifica o polo final de uma escala de valores cujo percurso é denotado pela transição. Por exemplo, a consequência de emagrecer não é necessariamente 'estar magro', mas 'estar mais magro’. Daí que estes verbos sejam frequentemente denominados "verbos incrementativos", "verbos de acabamento gradual" ou "realizações graduais" (BERTINETTO; SQUARTINI, 1995; FÁBREGAS, 2002; FERNÁNDEZ LAGUNILLA; MIGUEL, 1999).

Em termos semântico-argumentais, os verbos derivados com o operador sufixal -ecer tanto podem ocorrer em construções causativas como em construções incoativas. Vejamos o caso do verbo escurecer: 
a. O fumo escureceu a parede da cozinha.

b. A parede da cozinha escureceu. (causativa)

(incoativa)

Enquanto em (56b) se focaliza a aquisição de um estado pela entidade afetada do evento (perspetivação incoativa), em (56a) focalizase a causa que motiva esse evento, a qual ocupa a posição mais proeminente (sujeito) na estrutura sintática (perspetivação causativa). O estado a que chega a entidade afetada pode ser considerado um estado co-natural ao objeto, uma espécie de resultado da evolução natural (cf. 56b), ou então um estado produzível por influência de uma causa externa (cf. 56a), no sentido de que não se verificaria, pelo menos de forma tão intensa e evidente, sem essa influência.

Tal como escurecer, muitos verbos derivados em -ecer admitem participar em alternâncias de tipo causativo/incoativo, como se ilustra nos exemplos seguintes:
a. O calor endureceu o pão.
(causativo)
b. O pão endureceu.
(incoativo)

a. A morte do pai envelheceu-o. (causativo)

b. Ele envelheceu muito. (incoativo)

Podemos, pois, encontrar estes verbos em duas construções distintas: uma é uma construção transitiva e semanticamente causativa; a outra é uma construção intransitiva (inacusativa) de leitura incoativa. Na construção causativa, intervêm dois argumentos: uma entidade causadora, que ocupa a posição de sujeito, e uma entidade afetada, com a função de objeto direto. No uso não causativo, $\mathrm{o}$ verbo constrói-se com um só argumento, a entidade afetada, que nesta construção passa a ocupar a posição de sujeito sintático.

Não obstante ocorrerem preferentemente em construções incoativas, os verbos em -ecer não possuem, na sincronia atual, um valor semântico-aspetual específico que os oponha aos demais verbos deadjetivais e denominais. ${ }^{11}$ De facto, outros padrões derivacionais, afixais e não afixais, competem com ele na expressão da incoatividade e da causatividade. $O$ valor aspetual incoativo que tradicionalmente é atribuído aos verbos terminados em -ecer, ou seja, de 'início de um estado ou processo', apenas se manteve no verbo deverbal adormecer, sendo por isso residual na língua portuguesa. Talvez seja por isso que o Dicionário da Língua Portuguesa Contemporânea (2001), editado pela Academia das Ciências de Lisboa, não faça qualquer referência ao valor incoativo na entrada que dedica ao sufixo -ecer.

“-ecer elem. de form. (Do lat. -escěre). Exprime a noção de processo, acção. Enfraquecer, enlouquecer, enriquecer, anoitecer."

Note-se ainda que, como já foi referido em estudos anteriores (PEREIRA, 2007, 2009, 2016), as propriedades aspetuais que habitualmente são atribuídas aos afixos não determinam por si só, e de modo absoluto, a estrutura aspetual dos verbos derivados em que ocorrem. De facto, a variação apresentada pelos verbos derivados em termos semântico-aspetuais é, em grande parte, motivada pela natureza semântica das bases lexicais selecionadas. Para além disso, a informação codificada ao nível lexical pode ser alterada em função do tempo verbal, das características dos argumentos ativados pelo verbo e por modificadores aspetuais.

\section{CONSIDERAÇÕES FINAIS}

Neste artigo mostramos que os verbos em -ecer não expressam necessariamente o início de um estado ou processo, como algumas gramáticas referem. Tal acontece no verbo deverbal adormecer ('começar a dormir'), instanciação de um esquema formativo atualmente não produtivo na língua portuguesa. A compatibilidade com verbos auxiliares aspetuais como começar $a$, estar $a$,

${ }^{11}$ Pena (1993, p. 264) refere que os verbos sufixados com -ecer em espanhol carecem de um significado uniforme, ao contrário dos congéneres verbos latinos. Haouet (2000, p. 248-249), por sua vez, assinala que -ecer é um «marcador incoativo débil», pois não permite derivar verbos com um traço aspetual determinado. 
continuar a, deixar de, acabar de enfraquece essa tese e revela que estes verbos podem expressar eventos tanto incetivos, como permansivos, cessativos ou conclusivos. Mais do que a fase inicial do evento, os verbos em -ecer designam eventos delimitados que focalizam o estado final da mudança sofrida por uma entidade. Exprimem geralmente uma mudança em direção ao estado designado pela base derivacional (e.g. amanhecer, amarelecer, apodrecer, endurecer). De acordo com a sua estrutura [-] ou [+] durativa, subdividem-se em transições simples (e.g. emudecer, enraivecer) e transições graduais (e.g. amadurecer, amanhecer, endurecer, escurecer).

Como pudemos constatar, este estado de coisas caracteriza os verbos em -ecer ao longo da sua diacronia, encontrando-se já atestado português antigo. Já nos textos escritos na fase inicial do português, os verbos em -ecer denotam geralmente eventos durativos que culminam num ponto em que se atinge um novo estado. Em termos semântico-argumentais, verifica-se que a maior parte dos verbos em -ecer apresenta um uso incoativo, denotando a mudança sofrida pelo objeto sem qualquer referência explícita à causa de tal mudança. Em alguns enunciados, porém, estes verbos designam eventos causativos, em que um sujeito age de tal modo que provoca ou causa uma alteração do estado ou das propriedades de uma entidade.

A afirmação de que os verbos em -ecer são incoativos deve, portanto, ser mitigada e questionada, tanto no sentido aspetual de 'começo ou início de um estado ou processo', como no sentido semântico-argumental, na designação de eventos não causados ou internamente causados. Por um lado, a compatibilidade com os verbos auxiliares aspetuais demonstra que a maioria dos verbos com o constituinte sufixal -ecer denota eventos durativos que podem assumir tanto um aspeto incetivo, como o aspeto permansivo ou conclusivo. Por outro, se é verdade que estes verbos são preferencialmente usados em construções incoativas, muitos participam também na expressão de eventos causativos.

Continuamos, por isso, a considerar que os verbos em -ecer não possuem, na sincronia atual, um valor semântico-aspetual que os oponha de forma clara aos restantes verbos denominais e deadjetivais construídos em português. De facto, verbos que manifestam outros esquemas de construção (e.g. azedar, alargar, encurtar, esfriar, amenizar, intensificar) competem com eles na expressão da incoatividade e da causatividade.

\section{REFERENNCIAS}

ACADEMIA DAS CIÊNCIAS DE LISBOA. Dicionário da língua portuguesa contemporânea. Lisboa: Academia das Ciências de Lisboa / Editorial Verbo, 2001.

ALEXIADOU, A. On the morpho-syntax of (anti-)causative verbs. In: RAPPAPORT HOVAV, M.; DORON, E.; SICHEL, I. (ed.). Syntax, lexical semantics and event structure. Oxford: Oxford University Press, 2010. p. 177-203.

ALEXIADOU, A. The causative alternation revisited: constraints and variation. English Linguistics, v. 32, n. 1, p. 1-21, 2015.

ALLEN, A. S. Regrammaticalization and degrammaticalization of the inchoative suffix. In: ANDERSEN, H. (ed.). Historical linguistics 1993. Amsterdam/ Philadelphia: John Benjamins Publishing Company, 1995. p. 1-8.

BECHARA, E. Moderna gramática portuguesa. 37.ed. revista e ampliada. Rio de Janeiro: Nova Fronteira, 1999.

BERTINETTO, P. M.; SQUARTINI, M. An attempt at defining the class of 'gradual completion verbs'. In: BERTINETTO, P. M. et al. (ed.). Temporal reference, aspect and actionality. Turin: Rosenberg \& Sellier, v. 1, 1995. p. 11-26.

BLAYLOCK, C. The Romance development of the Latin verbal augment -sk-. Romance Philology, v. 28, p. 434-444, 1975.

BLUTEAU, R. Vocabulario portuguez e latino [...]. Coimbra: Collegio das Artes da Companhia de Jesus, 1712-1728. 
BORER, H. The causative-inchoative alternation: a case study in parallel morphology. The Linguistic Review, v. 8, p. 119-158, 1991.

CÂMARA JR., J. M. História e estrutura da língua portuguesa. 3.ed. Rio de Janeiro: Padrão Editora, 1979.

CARDOSO, J. Dictionarium ex lusitanico in latinum sermonem. Coimbra: João Álvares, 1562-1563.

CENTRO DE LINGUÍSTICA DA UNIVERSIDADE NOVA DE LISBOA. CIPM - Corpus informatizado do português medieval: Disponível em: https://cipm.fcsh.unl.pt/gencontent.jsp?id=4. Acesso em: 27 dez. 2020.

CENTRO DE LINGUÍSTICA DA UNIVERSIDADE NOVA DE LISBOA .DVPM - Dicionário de verbos do português medieval. Disponível em: https://clunl.fcsh.unl.pt/recursos-em-linha/dicionario-de-verbos-portugues-medieval-dvpm/. Acesso em: 07 jul. 2020.

CUNHA, C.; CINTRA, L. Nova gramática do português contemporâneo. 10.ed. Lisboa: João Sá da Costa, 1994.

FÁBREGAS, A. Los verbos de realización gradual: estructura léxica. Revista Española de Lingüística, v.32, n.2, p. 475-506, 2002.

FERNÁNDEZ LAGUNILLA, M.; MIGUEL, E. Relaciones entre el léxico y la sintaxis: adverbios de foco y delimitadores aspectuales. Verba, v. 26, p. 97-198, 1999.

FIGUEIREDO, C. Grande dicionário da língua portuguesa, v. 1. 25.ed. Venda Nova: Bertrand, 1996.

FONSECA, J. Aspectos centrais da semântica-sintaxe e pragmática dos predicados de sentimento. Diacrítica, n 13-14, p. 237-278, 1998-1999.

GLARE, P. G. W. (ed.). Oxford latin dictionary. Oxford: Oxford University Press, 1983.

GREENBERG, J. H. The last stages of grammatical elements: contractive and expansive desemanticization. In: TRAUGOTT, E. C.; HEINE, B. (ed.). Approaches to grammaticalization. Amsterdam and Philadelphia: John Benjamins, 1991, v. I, p. 301-314.

GRIMSHAW, J. Argument structure. Cambridge/MA: The MIT Press, 1990.

HAOUET, L. En torno a la relación entre morfología y sintaxis: la formación de los parasintéticos en español. Tesis (Doctoral) Universidad Autónoma de Madrid, Madrid, 2000.

HÄRTL, H. Conceptual and grammatical characteristics of argument alternations: the case of decausative verbs. Linguistics, v. 41, p. 883-916, 2003.

HASPELMATH, M. More on the typology of inchoative/causative verb alternations. In: COMRIE, B.; POLINSKY, M. (ed.). Causatives and transitivity. Amsterdam: John Benjamins, 1993, p. 87-120.

HOUAISS, A.; VILLAR, M. S.; FRANCO, F. M. M. (dir.). Dicionário Houaiss da língua portuguesa, v. III. Lisboa: Círculo de Leitores, 2003.

ILIESCU, M. Les suffixes d'álargissement verbaux. (Etat de la question. Evolution sémantique de -ESC / -ISC.). In: CALBOLI, G. (ed.). Latin vulgaire - Latin tardif II (=Actes du IIème Colloque International sur le latin vulgaire et tardif, Bologne, 1988). Tübingen: Max Niemeyer Verlag, 1990. p. 159-169.

KOONTZ-GARBODEN, A. Anticausativization. Natural Language and Linguistic Theory, v. 27, p. 77-138, 2009. 
LABELLE, M. La structure argumentale des verbes locatifs a base nominale. Linguisticae Investigationes, v. XVI, n. 2, p. 267-315, 1992.

LEVIN, B.; RAPPAPORT HOVAV, M. A preliminary analysis of causative verbs in English. Lingua, v. 92, p. 35-77, 1994.

LEVIN, B.; RAPPAPORT HOVAV, M. Lexical semantics and syntactic structure. In: LAPPIN, S. (ed.). The handbook of contemporary semantic theory. Oxford, Cambridge/MA: Blackwell Publishers, 1996. p. 487-507.

LEVIN, B.; RAPPAPORT HOVAV, M. Morphology and lexical semantics. In: SPENCER, A.; ZWICKY, A. M. (ed.). The handbook of morphology. Oxford, Malden: Blackwell Publishers, 1998. p. 248-271.

LIEBER, R. Lexical semantics, mapping in and from the lexicon, and the internal structure of words. In: MATOS, G. et al. (ed.). Interfaces in linguistic theory. Lisboa: APL / Edições Colibri, 1997, p. 221-240.

LIEBER, R .Morphology and lexical semantics. Cambridge/UK: Cambridge University Press, 2004.

MIGUEL, E.; FERNÁNDEZ LAGUNILLA, M. El operador aspectual se. Revista Española de Lingüística, v. 30, n. 1, p. 13-43, 2000.

OLIVEIRA, F. Tempo e aspecto. In: MATEUS, M. H. M. et al.. Gramática da língua portuguesa. 5.ed. revista e aumentada. Lisboa: Caminho, 2003.p. 127-178.

PENA, J. La formación de verbos en español: la sufijación verbal. In: VARELA, S. (ed.). La formación de palabras. Madrid: Taurus Ediciones, 1993, p. 217-281.

PEREIRA, R. Formação de verbos em português: afixação heterocategorial. Muenchen: Lincom Europa, 2007.

PEREIRA, R. Formação de verbos. In: RIO-TORTO, G. et al.. Gramática derivacional do português. 2.ed. Coimbra: Imprensa da Universidade de Coimbra, 2006. p. 297-355.

PEREIRA, R. “Não me aquenta, nem me arrefenta”. Considerações a propósito da origem e evolução dos verbos terminados em entar em português. Labor Histórico, v. 6, n. 1, p. 1-16, 2020.

PEREIRA, R. Unidade e diversidade semântica dos verbos derivados em português. Verba, v. 36, p. 15-46, 2009.

PIEL, J. M. Formação de palavras. In: ACADEMIA DAS CIÊNCIAS DE LISBOA, Dicionário da língua portuguesa. v. I. 2.ed. Lisboa: Imprensa Nacional - Casa da Moeda, 1976. p. xxii-xxviii.

PIÑON, CH. Modelling the causative-inchoative alternation. Linguistische Arbeitsberichte, v. 76, p. 273-93, 2001.

PUSTEJOVSKY, J. The syntax of event structure. Cognition, v. 41, p. 47-81, 1991.

RAMCHAND, G. C. Aspect and predication. The semantics of argument structure. Oxford: Clarendon Press, 1997.

RAPPAPORT HOVAV, M. Deconstructing internal causation. In: BAR-ASHER SIEGAL, E.; BONEH, N. (ed.). Perspectives on causation. Jerusalem studies in philosophy and history of science. Cham: Springer, 2020, p. 219-255.

RAPPAPORT HOVAV, M.; LEVIN, B. Building verb meanings. In: BUTT, M.; GEUDER, E. W. (ed.). The projection of arguments: lexical and compositional factors. Stanford, CA: CSLI Publications, 1998. p. 97-134. 
RAPPAPORT HOVAV, M.; LEVIN, B. Lexicon uniformity and the causative alternation. In: EVERAERT, M.; MARELJ, M.; SILONI, T. (ed.). The theta system: argument structure at the interface. Oxford: Oxford University Press, 2012. p. 150-176.

RAPPAPORT, M.; LEVIN, B.; LAUGHREN, M. Niveaux de représentation lexicale. Lexique, v. 7, p. 13-32, 1988.

SCHÄFER, F. The causative alternation. Language and Linguistic Compass, v. 3, p. 641-681, 2009.

SILVA, A. M. Diccionario da lingua portugueza [...]. Lisboa: Of. de Simão Thaddeo Ferreira, 1789.

VIEIRA, D. Grande diccionario portuguez / Thesouro da lingua portugueza. Porto: Em Casa dos Editores Ernesto Chardron e Bartholomeu H. de Moraes, 1871-1874.

ZAMBONI, A. La morfologia verbale latina in -sc- e la sua evoluzione romanza, appunti per una nuova via esplicativa. Quaderni patavini di linguística, v. 3, p. 87-138, 1982-1983.

\section{(๑) $\circledast \Theta$}

Recebido em 14/01/2021. Aceito em 22/02/2021. 